\title{
Character failings in the surgeon fallen from grace: a thematic analysis of disciplinary hearings against surgeons $2016-2020$
}

\section{ABSTRACT}

Surgeons are commonly evaluated with respect to outcomes and adherence to rules and regulations, rather than a true holistic examination of the character of the surgeon in question. We sought to examine the character failings of surgeons who faced fitness to practice enquiries under the Medical Practitioner Tribunal Service (MPTS) in the United Kingdom. In particular, we examined the absence of virtue as perceived through the lens of Aristotelian ethics using thematic analysis of tribunal hearing transcripts from 2016 to 2020. We identified three overarching themes that are explored in depth: "the god complex", "reputation over integrity" and "wounded pride". We hope to use this as the foundation for a re-examination of the place of phronesis in postgraduate surgical education, which we argue should be perceived as an exercise in character development and reformation rather than the simplistic teaching of skills to standardized outcomes.

\section{INTRODUCTION}

Surgeons are commonly evaluated with reference to their performance. This can be measured objectively during training by effectively grading actions in work-based assessments (WBAs) such as procedure-based assessments (PBAs) and direct observation of procedural skills in surgery (DOPs) ${ }^{1}$. This continues beyond training into independent practice where surgeons may be required to publish outcomes data and generate objective feedback on specific areas of care in the shape of patient-reported outcome measures (PROMs) and patient-reported experience measures (PREMs) among other formats ${ }^{2,}$. In effect, we ask surgeons to follow "rules" laid down by regulatory bodies such as the General Medical Council (GMC) ${ }^{4}$, and measure their performance in an act-centered ethical approach which is both deontological (how well surgeons "obey the rules" when acting) and consequentialist (whether they achieve desired outcomes as a result of their actions).

Previous work has highlighted the possible role for Aristotelian virtue ethics in postgraduate surgical education, focusing on the character of the individual rather than a particular act as the determinant of "goodness"5,6. The view that ethics should be concerned with character dates back to Aristotle, who claimed that virtuous actions are not good merely because they have the 
appropriate quality, but because the performer of these actions is in an appropriate frame of mind and proceeds from a "fixed and unchangeable disposition" to act from the right motivation. Action proceeding from judgment has been described as "a more authentic form of human endeavor than rule-generating or rule-following behaviour ${ }^{8}$. Aristotle went beyond claims about virtuous actions, he provided a framework for understanding the virtuous character which leads to virtuous action.

With this in mind, we sought to examine pervasive character failings in those surgeons who have "fallen from grace" to better understand the pitfalls that may have lead to disciplinary hearings for individuals who may have always "obeyed the rules" and appeared to have achieved objectively good outcomes up until their downfall.

\section{METHODS}

We requested previously published transcripts of conduct hearings involving surgeons carried out by the Medical Practitioner Tribunal Service (MPTS) in the UK between 2016 and 2020. There were a total of 68 Tribunal hearings involving surgeons during this period. The MPTS is a statutory committee of the GMC, accountable to GMC Council and the UK Parliament. It is completely independent in its decision-making and acts as an adjudication service, making decisions through tribunal hearings where fitness to practice of registrants has been called into question by the GMC.

A deductive thematic analysis of transcripts was carried out by the authors using the method described by Braun and Clarke ${ }^{9-11}$ and adhering to the Consolidated Criteria for Reporting Qualitative Research (COREQ) ${ }^{12}$. This method was selected for flexibility, ease of access, consistency and applicability to secondary sources. The method was deductive rather than inductive, as it sought to examine specifically for character flaws identified in the surgeons in question, as viewed against Aristotelian ethical ideals. The following stages were applied to all transcripts:

- Familiarisation: The authors worked through a pilot sample of transcripts to gain an understanding of the outline of the documents and language used.

- Coding: The complete set of transcripts was reviewed and blocks of salient text assigned "codes" which were both data-driven and research-driven. The authors worked separately on coding transcripts at this stage.

- Development of themes, sub-themes and overarching themes: "Codes" were used as the building blocks to establish "themes" and "sub-themes", including establishing theme relations e.g. hierarchical and/or lateral relations, visual thematic maps, etc.

- Validating and ensuring reliability: Reliability was derived from triangulation of codes, themes and sub-themes established independently and a 10\% overlap of cases reviewed 
by each author. Validation involved returning to source data to check for consistency with the themes derived.

- Defining and naming themes: Any themes identified individually were agreed by the authors, named and defined, ensuring there was no duplication of "central organising concepts" within separate themes (and that sub themes were "nested" appropriately).

- Interpretation and reporting: The final agreed manuscript was developed in its current format.

\section{RESULTS}

Analysis included all hearings held by MPTS from $1^{\text {st }}$ January 2016 until $30^{\text {th }}$ June 2020 . There were a total of 68 hearings reviewed. All surgeons involved were male and varied in their career stages, with the time since primary qualification ranging from 8 to 45 years. Sanctions handed down to surgeons by MPTS during this period are shown in Table 1 .

\begin{tabular}{lc} 
Sanction & Number of cases \\
No action & 4 \\
\hline Warning & 4 \\
\hline Conditions & 8 \\
\hline Suspension & 29 \\
\hline Erasure & 23
\end{tabular}

Table 1. Sanctions imposed by MPTS hearings against surgeons between $1^{\text {st }}$ January 2016 and $30^{\text {th }}$ June 2020

Table 2 demonstrates themes, subthemes and codes derived from the thematic analysis undertaken and agreed upon by the authors, whilst Figure 1 demonstrates a visual thematic map, demonstrating unexpected lateral relations between themes and subthemes. There were three overarching themes identified: "the god complex", "reputation over integrity" and "wounded pride". 


\begin{tabular}{|c|c|c|c|c|c|c|c|c|c|}
\hline \multicolumn{5}{|c|}{ The god complex } & \multicolumn{4}{|c|}{ Reputation over integrity } & Wounded pride \\
\hline \multicolumn{3}{|c|}{ Power plays } & Devaluing the patient & No safety net & \multicolumn{3}{|c|}{ Pursuit of glory } & \begin{tabular}{|l}
\multicolumn{1}{|c}{ Covering tracks } \\
Evading \\
responsibility/accountability \\
Dishonesty \\
Pursuing more invasive \\
treatment to correct/conceal \\
previous mistakes
\end{tabular} & \multirow[b]{2}{*}{$\begin{array}{l}\text { Childishness } \\
\text { Wounded pride } \\
\text { Volatility } \\
\text { Lack of restrain } \\
\text { Lack of insight } \\
\text { Self-centredness } \\
\text { Overreaction to } \\
\text { provocation } \\
\text { Excessive } \\
\text { sensitivity to } \\
\text { jugment on } \\
\text { performance } \\
\text { Identity irrevocably } \\
\text { tied to role and } \\
\text { unable to reconcile } \\
\text { threats to this } \\
\text { Unwillingness to } \\
\text { take criticism on } \\
\text { board } \\
\text { Quick to } \\
\text { transfer/apportion } \\
\text { blame } \\
\text { Vanity } \\
\text { Citing external } \\
\text { standards as } \\
\text { unreasonable } \\
\text { rather than } \\
\text { accepting falling } \\
\text { short of said } \\
\text { standards }\end{array}$} \\
\hline $\begin{array}{l}\text { Power play with patients/relatives } \\
\text { Superiority of knowledge as } \\
\text { potential for abuse } \\
\text { Abuse of power } \\
\text { Abuse/exploitation of trust } \\
\text { Untouchable } \\
\text { Undermining dignity to assert } \\
\text { superiority } \\
\text { Deception of chaperone/staff by } \\
\text { virtue of lack of } \\
\text { experience/confidence/knowledge } \\
\text { Hubris } \\
\text { Inability to perceive value in the } \\
\text { contributions of others } \\
\text { Keeping patients in the dark } \\
\text { Taking advantage of vulnerability } \\
\text { Transgressing boundaries } \\
\text { Playing on ignorance } \\
\text { Aggressive manner to assert } \\
\text { superiority }\end{array}$ & 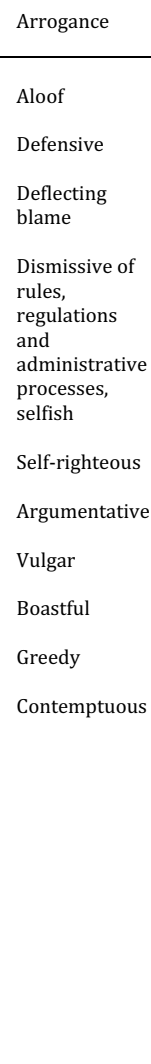 & \begin{tabular}{l}
\multicolumn{1}{c}{$\begin{array}{c}\text { Surgery as } \\
\text { panacea }\end{array}$} \\
$\begin{array}{l}\text { Not considering } \\
\text { conservative } \\
\text { management } \\
\text { options }\end{array}$ \\
$\begin{array}{l}\text { Overly zealous } \\
\text { belief in } \\
\text { surgery as a } \\
\text { panacea }\end{array}$
\end{tabular} & 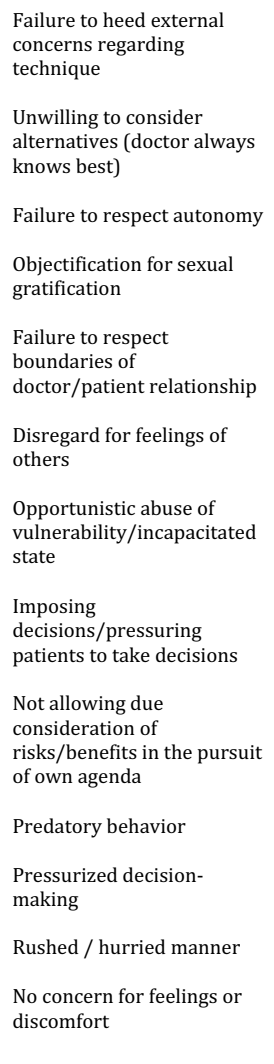 & 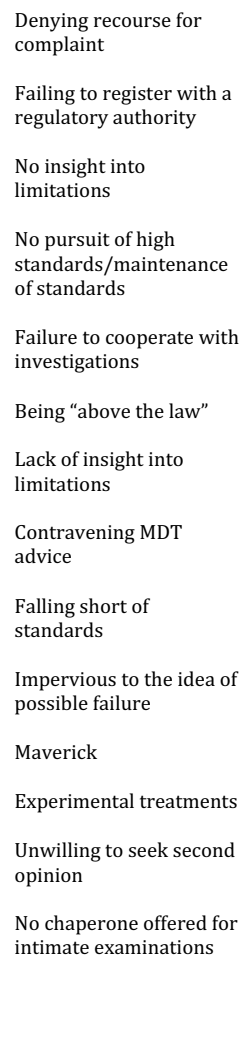 & 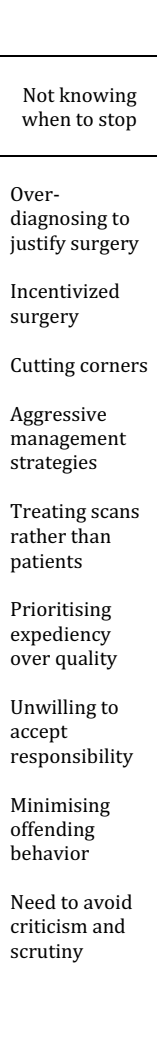 & 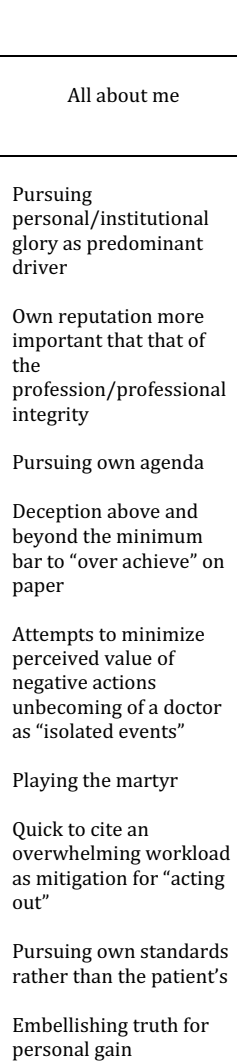 & $\begin{array}{l}\text { Risk taker } \\
\text { Not seeking } \\
\text { advice/second } \\
\text { opinion } \\
\text { Believes own } \\
\text { ability superior } \\
\text { to colleagues }\end{array}$ & $\begin{array}{l}\text { Evading } \\
\text { responsibility/accountability } \\
\text { Dishonesty } \\
\text { Pursuing more invasive } \\
\text { treatment to correct/conceal } \\
\text { previous mistakes } \\
\text { Self-preservation as } \\
\text { overriding principle } \\
\text { Deception in concealing } \\
\text { actions } \\
\text { Pursuing a false narrative } \\
\text { Minimising responsibility by } \\
\text { citing provocation } \\
\text { Preserving a fragile veneer of } \\
\text { integrity at any cost } \\
\text { "Whitewash" } \\
\text { Backtracking to preserve the } \\
\text { "show" of professionalism } \\
\text { Painting own version of } \\
\text { events } \\
\text { Wilfully deceptive } \\
\text { Deliberately misleading } \\
\text { Intending to deceive } \\
\text { Not backing down when } \\
\text { confronted with facts }\end{array}$ & \\
\hline
\end{tabular}

Table 2. Thematic analysis with overarching themes, themes, subthemes and code 


\section{The god complex}

Within this overarching theme, there were separate subthemes of "power plays", "devaluing the patient" and "no safety net". Surgeons who faced MPTS hearings seemed to have clear trends towards abusing positions of power and exploiting trust conferred upon them by patients and relatives. This often included deceiving patients and families, and on occasion more junior staff or allied health professionals, enabled by a disparity in knowledge levels. This extended in some cases to refusing to consider alternative treatment options and/or the opinions of others in the wider team, and an overly zealous belief in the value of surgery as a panacea. A recurring concept was surgeons failing to consider conservative management options, particularly when faced with the financial incentive of private practice remuneration. One case involved the MPTS tribunal "not disposed to accept [the surgeon's] explanation for not carrying out conservative measures.......[he] should have established that they had failed and/or were likely to fail before proceeding to surgery."

In many cases, surgeons had already received "warning shots" from their employers in advance of the MPTS hearing, but had failed to heed concerns expressed to them. This extended to denying patients the opportunity to voice concerns as a recurring theme, a lack of demonstrable insights into limitations or maverick behavior and a feeling of being "above the law" with no deference paid towards "safety nets" such as insurance or professional regulation in many instances.

The tendency to devalue and dehumanize patients encompassed a failure to respect autonomy, pressurized decision-making and on more than one occasion a failure to respect professional boundaries which at the extreme ends included objectification for sexual gratification and opportunistic abuse of vulnerable or incapacitated states. Concerns were raised by patients about overt examples of this behavior, including one surgeon who was described as "acting in a rushed, aggressive, insensitive and disrespectful manner", performing intimate examinations without the offer of a chaperone. Another surgeon who faced sanctions imposed by MPTS, repeatedly approached a patient with written correspondence to attempt to start a romantic relationship, stating at the outset to the patient that he was "taking advantage of the information I have about you and I am sure you will feel that I have dipped below your expectation and belief in me as a doctor."

\section{Reputation over integrity}

Within this overarching theme, subthemes were the "pursuit of glory" and "covering tracks". Surgeons demonstrated a recurring attitude of prioritizing personal achievement and glory over quality of care or professional integrity. This manifested as risk taking behavior and a need to avoid criticism and scrutiny. As this played out, many would appear to "play the martyr", citing 
overwhelming workloads and embellishing details to paint a picture that effectively shifted blame. In many cases, surgeons would attempt to conceal mistakes, which on occasion translated into redoing operations to cover up previous blunders (e.g. converting a unicompartmental joint arthroplasty to a total joint replacement upon realizing that the first surgery had involved the wrong compartment). These additional operations were done without informing patients of mistakes, and often involved concealing the previous errors from GPs in written correspondence.

Some cases highlighted a behavior pattern of deception beyond that which would satisfy minimum bar requirements, as in the case of one surgeon who falsified prior clinical experience far in excess of what would be required, "putting himself forward with a degree of exaggeration.....that he might be employed in a position he was not suited to, causing potential risks to patients." This deception was also extended to patients, where in another instance, the surgeon concerned "deliberately exaggerated the risk that the patient would develop cancer and advised either the necessity of undergoing continuing surveillance of their symptoms at further consultations or, on some occasions, the undertaking of various surgical procedures - none of which was necessary to maintain their health."

Essentially, there was a trend to pursue self-preservation at all costs, even if this meant deceiving patients and colleagues to preserve a veneer of false excellence, by relentlessly pursuing false narratives up to and including the MPTS hearing. On more than one occasion, transcripts remarked that the surgeons in questions failed to demonstrate insight or any attempts at remediation, effectively resulting in harsher sanctions.

\section{Wounded pride}

This followed on from previous subthemes but was deserving of its own place as an overarching theme. The pursuit of a seemingly spotless reputation by concealing mistakes and shifting blame also manifested as an unwillingness to accept criticism. On occasion, this would appear as excessive sensitivity to judgment on performance, overreaction to provocation and volatile behavior with staff and colleagues alike. In some cases, when confronted with standards to which they had not adhered, surgeons would go so far as to question the validity of the standards rather than their own performance. In one instance, where the surgeon in question faced criminal charges (the MPTS hearing erasing the registrant), it was stated that "during police interviews and throughout his trial, [the surgeon] maintained his innocence and adopted a position of arrogance." The complete unwillingness to consider the possibility of being at fault was glaring in this instance. The unwillingness to consult with colleagues also left some surgeons effectively "operating in a vacuum", where their clinical practice became progressively deviating from the norm of treatment provided. In the case of one registrant who repeatedly provided "experimental" treatment to patients with no evidence base, it was stated that he "failed to treat patients' conditions conservatively, resorting to surgery too early; undertook surgical procedures and interventions 
which were not clinically indicated; and failed to consult with colleagues." The same surgeon repeatedly "failed to communicate to his patients the risks of the procedures, their experimental nature, or the likelihood of their making conditions worse not better", as well as "repeatedly disregarding guidance about communicating adequately with patients, particular in relation to obtaining consent."

\section{Discussion}

Data available from the Health and Social Care Information Centre 2014 workforce census and Joint Committee on Surgical Training in 2015 estimate a total of 17,178 surgeons across all specialties, including 7.285 Consultants ${ }^{13}$. The cases discussed here therefore represent a very small proportion of surgeons, specifically $0.001 \%$ of surgeons per annum facing MPTS panels. It is interesting that all those involved were male surgeons. Women in surgery still represent a minority, although this appears to be increasing, with female surgeons accounting for $11 \%$ of consultants, but $30 \%$ of surgical trainees ${ }^{13}$. It has been noted that male doctors overall are far more likely to face disciplinary hearings and receive sanctions ${ }^{14-16}$. Previously postulated theories for this discrepancy have included differences in communication styles (suggesting that women communicate more effectively with patients), differences in the threshold of tolerance by the public and/or the regulatory body and differences in working patterns (fewer patient interactions as a result of higher rates of less than full time equivalent working among female doctors) ${ }^{17,18}$.

Furthermore, it was highlighted in the GMC commissioned report Fair to Refer? that employers and healthcare providers were more likely to refer doctors who obtained their primary medical qualification outside the UK and those who were from a black and minority ethnic (BME) background ${ }^{19}$. It is some small comfort that a follow-up study demonstrated that the seriousness of regulatory outcomes was unrelated to these characteristics, but rather to engagement with the process (attendance and legal representation), prompting the GMC to redefine support mechanisms for doctors facing tribunal proceedings ${ }^{20}$.

In the Nicomachean Ethics ${ }^{7}$, Aristotle highlighted the concept of enkrateia (loosely translated as "self-control") and its opposite akrasia as a dichotomy that is inherent to a person having sufficient self-mastery to "do the right thing". The aim of the virtuous life is eudaimonia ("flourishing"), achieved by pursuing the supreme good; something worth pursuing for its own sake because it is worthy of this approach. The virtuous life (arête) is the only life that can be worthwhile in Aristotle's vision of humanity. However, the pursuit of reputation, power, money and sexual gratification are recurring themes within the cases reviewed. The pursuit of these ends highlights a number of character flaws which are problematic in any ethical framework. We are interested in using Aristotle's concept of the golden mean to engage in ethical analysis because it focuses less on the wrong actions which are laid out clearly in the tribunal records, and more on the character 
of the person making problematic choices and performing harmful actions which flow from their character.

Aristotle laid out the doctrine of the mean, where habituation leads one to pursue virtue and avoid excess or deficiency. There are a number of virtues which are relevant to a better understanding of this group of surgeons, including courage, truthfulness and good temper, highlighted in Figure 2. The aim for a surgeon is to find an equilibrium, which is person and context specific. A 'good' surgeon is not just a technically proficient one, they are also a surgeon whose character aims for the mean between excess and deficiency in the moral choices inherent in a career in surgery. The tribunal records provide a view of the surgeon at the time of the events which led to the referral for fitness to practice and a contemporary record of their current character, as seen through character witnesses, employer statements, patient testimony and the personal statements the surgeon makes during the tribunal hearing. Thus our coding of character flaws was based on a longitudinal analysis rather than judgements about isolated incidents.

Using the golden mean, we can see that a surgeon often needs courage during the planning and conduct of an operation. Too little courage leads to cowardice, where the full ambition of an operation may not be achieved, whilst too much courage leads to rashness, where an operation is conducted without proper planning or in a way which increases the likelihood of surgical errors. In both the deficiency and excess, patient harm is more likely. A common theme for many cases was the overzealousness in surgery and regard of the scalpel as a panacea despite evidence to the contrary. Phronesis informs good judgment and it is commonly said that whilst the good surgeon knows when to operate, the excellent one knows when to stop. Take for instance comments about one surgeon who "repeatedly disregarded guidance about communicating adequately with patients" and "failed to communicate to his patients the risks of procedures, their experimental nature, or the likelihood of making conditions worse not better". Overreaching and greed (pleonexia) are vices highlighted by Aristotle's Ethics that are echoed here in the safeguarding of one's own reputation above that of the profession, impairing judgement ${ }^{7}$.

If truthfulness is the mean, then most surgeons in the data set had components of boastfulness which manifested in various ways throughout the tribunal record. The relentless pursuit of personal glory may lead surgeons who have fallen from grace to cut corners in the interests of expediency, cover their tracks and almost overcompensate. In some cases this may extend to falsifying case notes and job applications, in particular omitting checkered pasts, but in the worst instances this behavior can lead to repeated surgeries on uninformed patients to cover up mistakes. Magnanimity (megalopsuchia) stands in stark contrast to vanity and wounded pride in the Ethics and finds representation in the MPTS cases in additional behaviours such as playing the martyr and shifting the blame to institutional failings, surgeons citing themselves as the exception and pursuing a self-promotional narrative until the very end in an attempt to preserve an ever more fragile veneer of a pristine personal reputation, to the detriment of that of the profession ${ }^{7}$. 
Many surgeons also presented with an excess of irascibility (the tendency to be easily angered). Maintaining the mean of a good temper is challenging in stressful situations such as complex patient interactions and surgical procedures, but if the surgeons character is irascible, they are more likely to behave unprofessionally. Some surgeons demonstrated their irascible nature during the tribunal hearing, both verbally and in writing. Some surgeons declined to attend the tribunal hearing for a variety of reasons but chose to engage in argumentative written communication with the GMC prior to the Tribunal.

In certain cases, it was not possible to discern a precise set of character traits which fitted into a golden mean framework. Some surgeons had complex patterns of behaviours and attitudes which were extreme even for this data set. Abuse of trust in the pursuit of power can be seen in cases such as that of one surgeon whose behavior was described as "aggravated by the power imbalance between himself and those he subjected to his behavior." In other cases this took various forms including keeping patients and/or colleagues in the dark by abusing a disparity in knowledge and understanding, preying on vulnerabilities and transgressing the professional boundaries of the doctor-patient relationship ${ }^{21}$. Surgeons in many of the cases had a tendency to "dehumanize" the patient and denying recourse to a safety net of all the protection that would ordinarily be extended to a patient who is cared for and valued in their own right. This dehumanization by the worst elements of the medical profession has previously been highlighted by Foucault in his work The Birth of the Clinic, and can be seen at play in these cases ${ }^{22}$. Rousseau stated "a tile that falls off a roof may injure us more seriously, but it will not wound us so deeply as a stone thrown deliberately by a malevolent hand ${ }^{23}$." The issue of intent or volition is seen in many of the MPTS hearing transcripts, such as descriptions of the actions of one individual as "intentionally harmful", "a pattern of lies, deceit and exploitation of patients", representing "the antithesis of the Hippocratic Oath". The distinction between voluntary (hekousion) and involuntary (akousion) acts is clearly made by Aristotle in the Nicomachean Ethics as a marker of the representation of an unchanged disposition or character7. Indeed, this pattern of behavior is seen as the focus of deliberation in the Tribunal at sanction stage, where surgeons who failed to demonstrate insight or remediation over prolonged periods were more likely to receive increasingly severe sanctions, resulting in erasure where deemed necessary.

\section{Phronesis in surgical training}

One may wonder what the value is in citing character failings or examining surgeons fallen from grace through the lens of Aristotelian virtue ethics. A key consideration is that these dispositions or character traits may be amenable to change. Character flaws may manifest themselves early in training in behaviours such as overselling oneself or overstating experience (boastfulness), "gallows humour" or "black humour" (tastelessness), an unwillingness to accept criticism (vanity), 
a reluctance to ask for help (pride), regarding surgery as a panacea (greed and rashness) and failing to consider other options or concede to patient autonomy and choice.

Morally informed action requires self-exploration against standards of professionalism in terms of virtues, values, beliefs, attitudes, feelings and ideals. The practice of surgery embodies the development of wisdom through experiential learning (praxis) in the context of a community that fosters professional judgment, to be able to act within a tradition but also to critique it $^{24}$. By "reverse engineering", we may be able to identify these traits in trainees at the point of recruitment or early in training and habituate positive attributes (phronesis) rather than merely handing trainees a rule book and measuring tape. The hope is that one can be eudaimon through habituation, a learned process, making the case for this in postgraduate surgical education and training.

The concept of the golden mean per se is not sufficient of its own accord to underpin postgraduate surgical training. It is context specific for both the clinician and the patient at any given moment in time and the focus should be on enabling trainees to adjudicate conflicting values for a given situation, providing "an essential connection between seeing or understanding what is right or good and knowing how to do good 25 ." Bontemps-Hommen et $\mathrm{al}^{26}$ have proposed a new heuristic definition of phronesis in light of the complexities of modern medical practice that highlighting ever-changing practices and contexts whereby "the good appears to be fluid, is rarely quantifiable, and it cannot easily be generalized". The concept of practical wisdom (phronesis) is needed in postgraduate surgical training as a character reformation rather than just imparting practical skills within the limited ethical frameworks of duty and consequentalist based ethical systems ${ }^{27}$.

\section{REFERENCES}

1. Beard J, Bussey M. Workplace-based assessment. Ann R Coll Surg Engl 2007;89:158-160

2. Chou E, Abboudi H, Khan MS, et al. Should surgical outcomes be published? J R Soc Med 2015;108(4):127-135

3. Kingsley C, Patel S. Patient-reported outcome measures and patient-reported experience measures. BJA Educ 2017;17(4):137-144

4. General Medical Council. Good Medical Practice. (C) GMC 2013 [accessible online at https://www.gmc-uk.org/-/media/documents/good-medical-practice---english-20200128 pdf51527435.pdf?la=en\&hash=DA1263358CCA88F298785FE2BD7610EB4EE9A530]

5. Elledge R, Brennan PA, Mohamud A, Jones J. Phronesis and virtue ethics: the future of surgical training? Br J Oral Maxillofac Surg 2020;58(2):125-128

6. Hursthouse R. On Virtue Ethics. (C) Oxford University Press, 1999

7. Aristotle, Ross WD, Brown L. The Nicomachean Ethics. Oxford: Oxford University Press, 2009

8. Grundy S. The Curriculum: Product or Praxis. Falmer Press, London 1987

9. Braun V, Clarke V. Using thematic analysis in psychology. Qual Res Psychol 2006;3:77-101 
10. Braun V, Clarke V. Thematic analysis. In: H Cooper (Ed) APA Handbook of Research Methods in Psychology (Vol. 2, pp. 57-71). Washington DC: APA books, 2012

11. Braun V, Clarke V. Thematic analysis. In: A.C. Michalos (Ed.) Encyclopaedia of Quality of Life and Wellbeing Research. New York: Springer, 2014

12. Nowell LS, Norris JM, White DE, Moules NJ. Thematic analysis: striving to meet the trustworthiness criteria. Int J Qual Methods 2017;16:1-13

13. https://www.rcseng.ac.uk/news-and-events/media-centre/media-background-briefings-andstatistics/surgery-and-the-nhs-in-numbers/ [Accessed online 24th October 2020]

14. Alam A, Klemensberg J, Griesman J, Bell CM. The characteristics of physicians disciplined by professional colleges in Canada. Open Med 2011;5(4):e166-e172

15. Unwin E, Woolf K, Wadlow C, Dacre J. Disciplined doctors: does the sex of a doctor matter? A crosssectional study examining the association between a doctor's sex and receiving sanctions against their medical registration. BMJ Open 2014;4(8):e005405

16. Kohatsu ND, Gould D, Ross LK, Fox PJ. Characteristics associated with physician discipline: a casecontrol study. Arch Intern Med 2004;164:653-8

17. Bloor K, Freemantle N, Maynard A. Gender and variation in activity rates of hospital consultants. JR Soc Med 2008;101:27-33

18. Taragin MI, Wilczek AP, Karns ME, et al. Physician demographics and the risk of medical malpractice. Am J Med 1992;93(5):537-542

19. General Medical Council. Fair to Refer? (C) GMC 2019 [accessible online at https://www.gmc-uk.org/_media/documents/fair-to-refer-report pdf-79011677.pdf]

20. Caballero JA, Brown SP. Engagement, not personal characteristics, was associated with the seriousness of regulatory adjudication decisions about physicians: a cross-sectional study. BMC Med 2019;17(1):211

21. Dyer C. Surgeon who made repeated sexual comments about staff is suspended for nine months. BMJ 2019;364:i255

22. Foucault M. The Birth of the Clinic: An Archaeology of Medical Perception. London (C) Tavistock 1973

23. Rousseau JJ, Butterworh CE. The Reveries of the Solitary Walker. New York @ New York University Press 1973

24. de Cossart L, Fish D (Eds.) Cultivating a thinking surgeon: new perspectives on clinical teaching, learning and assessment. tfm Publishing Ltd, Shrewsbury 2005

25. Pellegrino ED, Thomasma DC. The Virtues in Medical Practice. Oxford @ OUP 1993

26. Bontemps-Hommen CMML, Baart A, Vosman FTH. Practical wisdom in complex medical practices: a critical proposal. Med Health Care Philos 2019;22(1):95-105

27. Burnyeat MF. Aristotle on learning to be good. In: Rorty AO (Ed) Essays on Aristotle's Ethics (C) University of California Press 1980 